\title{
TRANSPOSIÇÃO DO MÚSCULO RETO DO ABDOME PARA CORREÇÃO DE DEFEITO IATROGÊNICO NO DIAFRAGMA EM CÃES
}

\author{
RECTOS ABDOMINIS MUSCLE FLAP FOR REPAIR OF \\ IATROGENIC DIAPHRAGMATIC DEFECTS IN DOGS
}

\author{
Renato Xavier Faria ${ }^{1}$ Ney Luís Pippi ${ }^{2}$ Luciana Oliveira de Oliveira ${ }^{3}$ Luciana Dambrósio Guimarães ${ }^{4}$ \\ Alexandre Mazzantí ${ }^{4}$ Alonso Gabriel Pereira Guedes ${ }^{5}$
}

RESUMO

Neste experimento, foram utilizados 6 cães, com o objetivo de avaliar a viabilidade do músculo reto do abdome pediculado para correção de defeito no diafragma. O músculo foi dissecado até próximo sua inserção e deslizado para a cavidade abdominal através de uma incisão paracostal. Após a formação de um defeito no diafragma de aproximadamente $4 \times 10 \mathrm{~cm}$, o músculo reto do abdome foi fixado com pontos de Wolff com fio de seda 2-0. Os animais foram observados por um período de tempo determinado de 15, 30 e 60 dias, quando foram operados novamente para observação macroscópica e microscópica. Tecido conetivo e áreas de hemorragia entre o retalho $e$ diafragma, com tecido de granulação de maturidade média, foram observados no material das biópsias aos 15 dias. Aos 30 dias, foi notado pouco tecido de granulação que, aos 60 dias, era maduro. Na região do implante, foi verificada integração tecidual entre o músculo reto do abdome e diafragma com total oclusão do defeito diafragmático, formação de tecido de granulação, onde foram observadas aderências do fígado, lobo pulmonar caudal, estômago e omento. $O$ músculo reto do abdome pediculado pode ser indicado para correção de defeitos no músculo diafragma, havendo uma completa integração tecidual na região do implante.

Palavras-chave; cão, diafragma, enxerto, músculo

\section{SUMMARY}

With the objective of analyzing the use Rectus abdominis muscle flaps for repair of large diaphagmatic defects, when direct suture is impossible, six dogs underwent surgery. The
Rectus ahdominis muscle was dissected up to its insertion and was introduced into the abdominal cavity through a paracostal incision. A defect of $4 \times 10 \mathrm{~cm}$ was created in the diaphragmatic muscle and the flap was sutured to the edges of the defect with horizontal mattres suture with 2-0 silk. Animais were clinically evaluated every day at the post-operative period. Biopsies and macroscopic observation were done at the $15^{\text {th }}, 30^{\text {th }}$ and $60^{\text {th }}$ day. Connective tissue and hemorrhagic areas among the flap and the diaphragm, and granulation tissue with median maturity were observed in the biopsy material at the $15^{\text {th }}$ day. At the $30^{\text {th }}$ day, few granulation tissue among the muscles were observed. At the $60^{\text {th }}$ day, there was mature granulation tissue. Adherence ocurred in the region of the implant with the liver, caudal pulmonar lobe, stomach and omentun. The Rectus abdominis muscle can be used to correct defects in the diaphragm with a complete tissue integration in the implanted region.

Key words; dog, diaphragm. graft, muscle.

\section{INTRODUÇÃO}

A parede do diafragma pode ser acometida por alterações congénitas ou adquiridas (RAISER, 1994), que podem permitir a passagem de vísceras da cavidade abdominal para a torácica ou vice-versa, determinando a formação de hérnia diafragmática (JOHNSON, 1998).

\footnotetext{
${ }^{1}$ Médico Veterinário. MS, Hospital Veterinário, Universidade Federal de Santa Maria (UFSM), 97105-900, Santa Maria - RS. E-mail: faria@lince.hcv.ufsm.br. Autor para correspondência.

${ }^{2}$ Médico Veterinário. PhD., Professor Adjunto, Departamento de Clínica de Pequenos Animais, UFSM.

${ }^{3}$ Médico Veterinário. MS Hospital de Clínicas Veterinária, Universidade Federal do Rio Grande do Sul.

${ }^{4}$ Médicos Veterinário. Alunos do Programa de Pós-Graduação em Cirurgia Veterinária, UFSM.

${ }^{5}$ Acadêmico do Curso de Medicina Veterinária. UFSM.
} 
Conforme a extensão da lesão no diafragma, uma sutura aproximando as bordas da ferida é suficiente para cicatrização do músculo. Mas, grandes defeitos como necrose decorrente de infecção, traumatismo, extensa ressecção do músculo por neoplasia, e nas hérnias crónicas, a contração muscular e retração cicatricial não permitem aproximação das bordas para a síntese, sendo indicada hemiopiastia (BARREIROS et ai., 1996).

Para reparo do diafragma foram utilizados vários métodos, como malhas sintéticas absorvíveis e não absorvíveis, "flaps" musculares, enxertos autógenos (ROSENKRANTZ \& COTTON, 1964; HELPHREY, 1982; BIANCHI et al., 1983; LEVINE， 1987; SWEET \& WATERS, 1991; BOUDRIEAU, 1996), vísceras (HELPHREY, 1982), enxerto de omento (BRIGHT \& THACKER, 1982; BOUDRIEAU, 1996; JOHNSON, 1998), segmento livre de peritônio muscular do músculo transverso do abdome (EURIDES et al., 1994), segmento de músculo grande dorsal autólogo (BARREIROS et al., 1996). HELPHREY (1982) utilizou retalho do músculo transverso do abdome e peritônio em hérnias crónicas e DALECK $\boldsymbol{e t} \boldsymbol{a l}$. (1988), peritônio de bovino conservado em glicerina. MATSUMOTO et al. (1996) utilizaram pericárdio canino tratado com polyepoxy conservado em solução alcoólica a $70 \%$, para correção de defeitos experimentais.

As possíveis abordagens cirúrgicas para o músculo diafragma são a paracostal (EURIDES et al; 1994), laparotomia na linha média, esternotomia mediana, toracotomia intercostal e toracotomia transesternal. Os fatores que influenciam a escolha de determinada abordagem são a possibilidade de localizar o lado herniado, o tempo decorrido desde início da sintomatologia e as possíveis aderências (JOHNSON, 1998).

Para síntese do músculo diafragma, RAISER (1994) recomendou iniciar a sutura a partir da porção de mais difícil acesso para o mais fácil com pontos de Wolff superpostos por sutura de Kirschner, de fio mononailon 2-0 ou 3-0. EURIDES et al. (1994) utilizaram, para fixação do implante, pontos isolados simples e fio de poliglactina 910, número 3-0. WOUK et ai. (1980) aproximaram as bordas do orifício hemiário, com fio de categute cromado em um grupo e seda em outro, comparando a evolução cicatricial. Já BARREIROS et ai. (1996) utilizaram na reconstituição da lesão do diafragma a sutura de Wolff e o fio de poliglactina 910.

Diversos tipos de aderências foram verificadas ao serem utilizados implantes para reparar o defeito muscular nas hérnias diafragmáticas. EURIDES et al. (1994) relataram que, no local onde foi removido o segmento de peritônio para ser implantado no músculo diafragma, encontraram aderências com o omento maior e no local do enxerto, com o fígado e vesícula biliar, pulmão e pericárdio. Já BARREIROS et ai. (1996), implantando segmentos do músculo grande dorsal, relataram leves aderências entre lobos hepáticos e/ ou pulmonares. Já o fígado aderido ao enxerto foi observado no diafragma dos cães implantados com peritônio bovino (DALECK $\boldsymbol{e t}$ al., 1988), enquanto ROSENKRANTZ \& COTTON (1964) observaram aderências do fígado, estômago, baço e pulmão ao utilizar malhas sintéticas absorvíveis ou não absorvíveis para reparar as rupturas diafragmáticas.

RAISER (1994) restabeleceu a pressão negativa torácica por insuflação pulmonar por ocasião do último ponto do primeiro plano de sutura e drenou o pneumotórax residual por toracocentese, com agulha hipodérmica $30 \times 10$, seringa de vidro e torneira de três vias. Já EURIDES et al. (1994) utilizaram apenas a insuflação forçada dos pulmões por alguns segundos, para forçar a saída de ar existente na cavidade pleural, antes de realizar o último ponto.

O presente trabalho teve como objetivo avaliar a disponibilidade e a viabilidade do músculo reto do abdome pediculado para correção de defeitos diafragmáticos em cães.

\section{MATERIAL E MÉTODOS}

Foram utilizados 6 cães ( 2 machos e 4 fêmeas) sem raça definida, pesando entre 8 e 16kg, provenientes do Biotério Central da Universidade Federal de Santa Maria. Esses cães foram vermifugados, adaptados ao canil e alimentados com ração comercial por um período de sete dias.

Os animais foram tranquilizados com cloridrato de acepromazina ${ }^{\mathrm{a}}$ a $1 \%(0, \mathrm{lmg} / \mathrm{kg})$. A anestesia foi induzida com tiopental sódico ${ }^{\mathrm{b}}$ a $2,5 \%$ $(12,5 \mathrm{mg} / \mathrm{kg})$, e mantidos em plano anestésico com halotano $^{c}$ em $100 \%$ de oxigênio em circuito semifechado, com respiração por pressão positiva intermitente. Como antibiótico profilático, foi utilizada ampicilina sódica ${ }^{\mathrm{d}}$ na dose de $20 \mathrm{mg} / \mathrm{kg} \mathrm{IV}$, cerca de 30 minutos antes do início da cirurgia. Os animais foram posicionados em decúbito dorsal e a antisepsia do local foi feita com álcool-iodo-álcool.

Através de uma incisão mediana préretro-umbilical de pele e tecido subcutâneo, o músculo reto do abdome foi liberado dessas duas estruturas. Paralelamente e próximo à linha alba, foi incisada a aponeurose do músculo reto do abdome, possibilitando a dissecação desse músculo, assim como das aponeuroses dos músculos oblíquo abdominal externo, interno e transverso do abdome. $\mathrm{O}$

Ciência Rural, v. 30, n. 4, 2000. 
músculo reto do abdome foi liberado na sua inserção caudal, rebatido cranialmente, ficando preso ao arco costal e envolvido, temporariamente, por uma compressa embebida com solução fisiológica. Os ramos dos vasos epigástricos caudais foram ligados. Após esse procedimento, uma incisão abdominal paracostal permitiu o deslizamento do músculo para dentro da cavidade abdominal. A seguir, foi efetuada abordagem pré-retro-umbilical na linha alba, afastamento das vísceras para melhorar a visualização e o acesso do diafragma, e colocação de dois pontos de reparo para produzir um defeito diafragmático de aproximadamente $4 \times 10 \mathrm{~cm}$. O músculo reto do abdome foi, então, tracionado e posicionado sobre o defeito, iniciando-se sua sutura, com o diafragma em pontos de Wolff com fio de $\operatorname{seda}^{\mathrm{e}}$ 2-0. Antes de apertar o último ponto que vedava a cavidade torácica, os pulmões foram insuflados para obtenção de expansão máxima e restituição da pressão negativa. No fechamento da linha alba, foram utilizados pontos de Sultan. O tecido subcutâneo restante foi concluído com sutura contínua simples, colocando-se na pele pontos isolados simples, sendo nessas estruturas utilizado fio de naylon grilon ${ }^{\mathrm{f}} 0,30$. Imediatamente após o término da cirurgia, foi feita toracocentese utilizando-se agulha $30 \times 8$, acoplada a uma seringa com torneira de três vias, para o restabelecimento da pressão negativa.

No pós-operatório imediato, os animais receberam antiinflamatório à base de flunixin meglumine ${ }^{\mathrm{g}}$ na dose de $1,1 \mathrm{mg} / \mathrm{kg}$ IV e IM por mais 2 dias e foram avaliados diariamente até o final do experimento, quando os animais foram sacrificados e necropsiados.

Em todos os cães, foram realizadas biópsias aos 15 e 30 dias de pós-operatório. Os animais foram submetidos ao mesmo protocolo anestésico, sendo removido, para análise, fragmentos da região de implantação: músculo reto do abdome e diafragma. Aos 60 dias, os animais foram necropsiados e coletado material para exame histopatológico. $\mathrm{O}$ material assim obtido foi fixado em formol tamponado, posteriormente processado e corado por Hematoxilina e Eosina.

\section{RESULTADOS}

O acesso cirúrgico por laparotomia proporcionou a produção do defeito na parede do diafragma, e sua correção com a transposição do músculo reto do abdome. A relação comprimento base do pedículo muscular foi suficiente para garantir a vedação do defeito e aporte sanguíneo; o novo posicionamento não causou torção vascular.
O aspecto macroscópico do enxerto, aos 15 dias, era de um tecido de granulação espesso. Aos 30 dias, esse tecido encontrava-se contraído com menor espessura, semelhante ao encontrado aos 60 dias. A neovascularização estava presente durante as observações.

Na microscopia das biópsias obtidas aos 15 dias, entre os músculos reto do abdome e diafragma, foram encontrado tecido mixóide com presença de áreas hemorrágicas, tecido de granulação medianamente maduro e reação granulomatosa ao fio de sutura (granuloma de sutura). Aos 30 dias, a área do tecido de granulação observada entre os músculos reto do abdome e diafragma era menor, sendo que na porção muscular abdominal havia presença de tecido de granulação, às vezes, com áreas de hemorragia e granulomas de sutura. Aos 60 dias, visualizou-se tecido de granulação maduro entre os músculos reto do abdome e diafragma com granulomas de sutura (Figura 1). Ocasionalmente, ocorreu a presença de macrófagos e polimorfonucleares, nas biópsias dos três grupos.

\section{DISCUSSÃO}

O local para a produção do defeito foi na porção muscular do diafragma que, além de ser a região de maior ocorrência de lesões dilacerantes, possibilitou a produção do defeito, sem considerar o lado de maior ocorrência da lesão, pois o objetivo foi a observação clinica pós-cirúrgica dos pacientes, e as características macro e microscópica do local do implante.

A laparotomia na linha média descrita por JOHNSON (1998), como uma das técnicas para abordar o diafragma e correção de lesões no

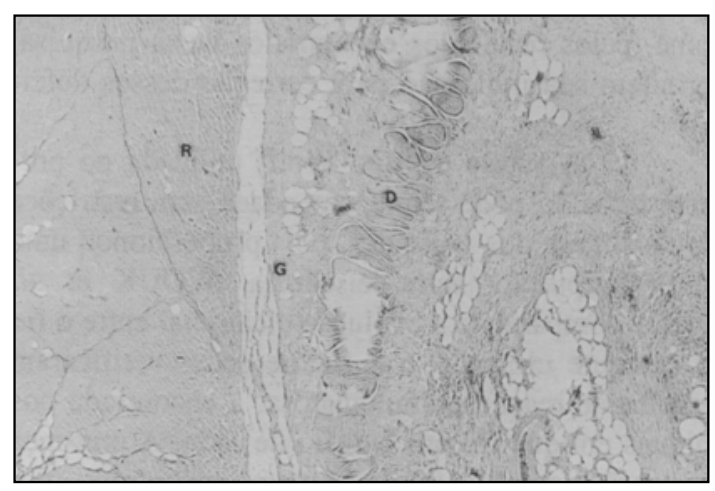

Figura 1 - Aspecto microscópico da transposição de músculo reto do abdome para corrigir defeito no diafragma. Observar a área de integração tecidual aos 60 dias de pós-operatório. Nota-se presença de tecido de granulação maduro $(\mathrm{G})$ entre os músculos reto do abdome (R) e diafragma (D). (HE 2,5x)

Ciência Rural, v. 30, n. 4, 2000. 
músculo, foi a escolhida para o acesso, pois, além da facilidade na liberação do músculo reto do abdome através de uma incisão paramediana, facilitou o afastamento das vísceras abdominais para a produção do defeito no diafragma e, na sequência, a sutura do músculo reto do abdome sobre o defeito. Não foi necessária a utilização de outras técnicas utilizadas por EURIDES et al. (1994) e JOHNSON (1998).

Os vários tipos de implantes e enxertos testados para reparar os defeitos no músculo diafragma e a busca de novas alternativas, ou até mesmo o aperfeiçoamento de técnicas já existentes, mostraram a preocupação dos cirurgiões com a reconstituição de um músculo que é vital para a sobrevivência de seres humanos e dos animais. Pelas avaliações clínicas e macroscópicas, pode-se deduzir que o músculo participou efetivamente da reparação contribuindo para o restabelecimento da atividade anatotomo-fisiológica do diafragma, pela boa integração na enxertia, que foi favorecida pela irrigação mantida na porção cranial do músculo reto do abdome.

Pode-se observar que o músculo reto do abdome possuía limitações quanto à sua largura, mas sua extensão foi apropriada para correção de defeitos alongados na porção ipsolateral do diafragma, em sua porção dorso cranial. Segundo BARREIROS $\boldsymbol{e t}$ al. (1996), a cicatrização do diafragma depende da extensão da lesão e da sutura utilizada para aproximar as bordas da ferida. Em casos de grandes lesões no diafragma, semelhantes às realizadas nos cães desta pesquisa, como as necroses decorrentes de infecções, extensas ressecções do músculo em neoplasias, hérnias diafragmáticas crónicas, onde a contração muscular e retração cicatricial não permitem a aproximação das bordas do músculo para síntese, a hemioplastia com o músculo reto do abdome, pelos resultados encontrados nesta pesquisa, permitem sua indicação para correção desses defeitos.

A sutura do tipo Wolff utilizada no presente trabalho pode ser recomendada sem restrições para a síntese dos músculos, pois proporcionou uma ótima coaptação, sem deiscência. WOUK et al. (1980), comparando a evolução cicatricial entre o fio de categute cromado e o fio de seda, verificaram semelhante reação granulomatosa, à encontrada nos animais em que foi usado o fio de seda. A presença de reação com o fio de sutura encontrado por BARREIROS et al. (1996), no músculo diafragma, confere com as observações encontradas no presente experimento.

Quanto às aderências ocorridas no diafragma, o fígado foi a víscera mais envolvida, seguido do lobo pulmonar caudal, estômago e omento.
Essas aderências viscerais foram também encontradas por ROSENKRANTZ \& COTTON (1964), com exceção do baço. DALECK $\boldsymbol{e t} \boldsymbol{a l}$. (1988); EURIDES $\boldsymbol{e}$ t al. (1994) e BARREIROS $\boldsymbol{e}$ al. (1996) encontraram somente aderências do fígado e lobo pulmonar. Tanto as aderências na face abdominal como torácica do diafragma não apresentaram manifestação clínica.

A integração entre o músculo reto do abdome e o diafragma observado neste experimento foi confirmada pela redução do tecido de granulação no período entre 15 e 30 dias, mantendo-se sem mudanças até os 60 dias. Isso contrapõe-se ao observado por EURIDES et al. (1994), que descreveram, nos 15 e 30 dias do pós-operatório, uma percentagem de fibrose sem diferença significativa, porém com significância se comparada à ocorrida até o sétimo dia. MATSUMOTO et $\boldsymbol{a l}$. (1996) relataram a presença de neovascularização, que também foi observada no presente trabalho. As observações microscópicas de MATSUMOTO $\boldsymbol{e t}$ al. (1996) demonstraram, aos 30 dias, moderada infiltração de tecido conjuntivo e células inflamatórias, com aumento de tecido conjuntivo aos 60 dias. Na pesquisa aqui realizada, a diferença foi aos 60 dias quando se encontrou tecido de granulação maduro. Essa maturação foi favorecida pelo uso do enxerto pediculado que proporcionou maior aporte sanguíneo ao local de fixação.

\section{CONCLUSÕES}

O músculo reto do abdome pediculado pode ser indicado para correção de defeitos no músculo diafragma, havendo uma completa integração tecidual entre os mesmos. No entanto, apresenta limitação quanto a sua largura, não podendo ser usado em defeitos largos. Quanto ao comprimento, é um músculo longo o suficiente para corrigir defeitos dorso-craniais do diafragma através da cavidade abdominal.

\section{FONTES DE AQUISIÇÃO}

a. Acepran 1\%, Laboratório Andrômaco, São Paulo - SP.

b. Thionembutal, Abbott Laboratórios do Brasil Ltda., São Paulo - SP.

c. Fluothane, Laboratórios Wellcome-Zeneca Ltda., Cotia - SP.

d. Ampicilina Sódica, Bristol-Myers Squibb Brasil S/A., Santo Amaro - SP

e. Seda 2-0, Cirumédica S.A., Cotia - SP.

f. Linha de Pesca Grilou, São Bernardo do Campo - SP

g. Banamine, Schering-Plough Veterinária, Rio de Janeiro - RJ.

\section{REFERÊNCIAS BIBLIOGRÁFICAS}

BARREIROS, L.J., RODASKI, S., SUSKO, I., et al. Uso experimental do músculo grande dorsal autólogo na reparação dos grandes defeitos diafragmáticos no cão. Revista Setor Ciências Agrarias, v.15, n.1, p.141-150,1996.

Ciência Rural, v. 30, n. 4, 2000. 
BIANCHI, A., DOIG, C.M., COHEN, S.J. The reverse Latissimus dorsi flap for congenital diaphragmatic hérnia repair. Journal of Pediatric Surgery, v.18, n.5, p.560563,1983 .

BOUDRIEAU, R.J., Hérnia diafragmática traumática. In: BOJRAB, M.J. Técnicas atuais em cirurgia de pequenos animais. 3 ed. São Paulo: Roca, 1996. cap.17,p.293-295.

BRIGHT, R.M., THACKER, H.L. The fonnation of an omental pedicle flap and its experimental use in the repair of a diaphragmatic rent in the dog. Journal of the American Animal Hospital Association, v. 18, p.283-289,1982.

DALECK, C.R., ALESSI, A.C., COSTA NETO, J.M., et al. Substituição de um retalho diafragmático de cão por peritônio de bovino conservado em glicerina: estudo experimental. Ars Veterinária, v.4, n.1, p.53-61,1988.

EURIDES, D., NIGRO, A.J.T., GOLDENBERG, S., et al. Reparo de defeito provocado no diafragma de cães com segmento livre peritônio-muscular: estudo experimental. Acta Cirúrgica Brasileira, v.9, n.3, p.131-135,1994.

HELPHREY, M.L. Abdominal flap graft for repair of chronic diaphragmatic hernia in the dog. Journal of the American Veterinary Medicai Association, v.181, n.8, p.791-793, 1982.

JOHNSON, K.A. Hérnia diafragmánca, pericárdica e hiatal. in:
SLATTER, D. Manual de cirurgia de pequenos animais. 2ed. São Paulo: Manole, 1998,. cap.37. p.559-577.

LEVINE, H.S. Diaphragmatic hernia. Veterinary Clinics of North América: Small Animal Practice, v.17, n.2, p.411430,1987

MATSUMOTO, H., OGUCHI, Y., MIYAKE, Y., et al. The use of epoxy patch grafts for the repair of experimentally-created diaphragmatic defects in dogs. Journal Veterinary Medicine Science, v.58, n.7, p.685-687,1996.

RAISER, A.G. Hemiorrafia diafragmática em cães e gatos. Relato de 22 casos e proposição de técnica para corrigir rupturas freno-costais. Brarilian Journal of Veterinary Research and Animal Science. v.31, n.3/4, p.245-251,1994.

ROSENKRANTZ, J.G., COTTON, E.K. Replacement of left hemidiaphragm by a pedicled abdominal muscular flap. Journal of Thoracic Cardiovascular Surgery, v.48, n.6, p.912-920,1964.

SWEET, D.C., WATERS, D.J. Role of surgery in the management of dogs with pathologic conditions of the thorax - part II. Compendium on Continuing Education for the Practidng Veterinarian, v.13, n.1 1, p.1671-1676,1991.

WOUK, A.F.P.F., PIPPI, N.L., SANTOS, M.N., dos, et ai. Resposta do tecido diafragmático às suturas com seda e categute cromado em cães. Revista Centro de Ciências

Ciência Rural, v. 30, n. 4, 2000. 
Rurais, v.10, n.3, p.219-223,1980.

Ciência Rural, v. 30, n. 4, 2000. 